\title{
Um ajuste justo ou mais alguns passos atrás para a educação básica pública no Brasil?
}

\author{
Eduardo Carvalho Ferreira ${ }^{1}$ \\ ORCID: 0000-0003-3750-9794
}

\section{Resumo}

Neste artigo, iremos apresentar e discutir o relatório Um ajuste justo: análise da eficiência e equidade do gasto público no Brasil (2017), produzido pelo Banco Mundial para conjecturar acerca da necessidade de um ajuste fiscal radical para sanar as finanças e os problemas orçamentários do país. 0 relatório em questão apresenta alguns argumentos e estratégias para a execução de um ajuste das contas públicas, em especial, para setores como saúde, educação, previdência social, dentre outros. Partindo de uma abordagem crítica acerca das recomendações do Banco para a educação básica pública brasileira, questionamos as diretrizes expressas no documento, que apontam para a necessidade de contingenciamentos e cortes no orçamento como forma de melhorar as contas e equilibrar a razão investimento/resultados. 0 relatório ampara-se em uma econometria que busca legitimar a todo custo a tese que vê na política fiscal contracionista o melhor caminho para intervir na educação básica pública. Ao longo do texto, discutimos se isso é factível considerando o nosso contexto histórico de subfinanciamento, onde, diferentemente de outros países mais ricos e menos desiguais, jamais alcançamos um patamar de investimentos suficientes para garantir o acesso, a permanência e a qualidade na educação básica.

\section{Palavras-chave}

Educação Básica - Ajuste fiscal - Austeridade - Banco Mundial - Justiça social.

\section{A fair adjustment or just a few extra backward steps for the public basic education in Brazil?}

\section{Abstract}

This article aims to present and discuss the report A Fair Adjustment: Efficiency and Equity of Public Spending in Brazil (2017) produced by The World Bank, in order to

1- Senac São Miguel Paulista, São Paulo, SP, Brasil. Contato: eduardo.cferreira2020@gmail.com. 
analyze the need for a radical fiscal adjustment aimed to solve the financial and budgetary issues of the country. The report under study presents some arguments and strategies for the implementation of a public spending adjustment, especially for sectors such as health, education, social security, and others. Through a critical approach in relation to the recommendations of the Bank directed at the Brazilian public basic education, the guidelines expressed in the document were questioned. These guidelines point to the need of budgetary contingencies and cutting as methods of improving public accounts and of balancing the investment/returns ratio. The report is grounded on an econometrics that seeks to legitimate, at all costs, the thesis that regards the contractionist fiscal policy as the best path to intervene in public basic education. Throughout the text, a discussion about the feasibility of such a policy will be presented, taking into consideration our historical context of underfunding, in which, unlike other countries that are richer and less unequal, Brazil has never reached the necessary investment level to guarantee access, permanence and quality for people in basic education.

\section{Keywords}

Basic education - Fiscal adjustment - Austerity - The World Bank - Social justice.

\section{Introdução}

Como a educação básica pública de um país evoluiu, em pouco tempo, menos de uma década, de um cenário que parecia mais promissor - ainda que remediado por interesses reservados ao fundamentalismo de mercado - com iminentes perspectivas de melhora no grau de investimento, vide a promulgação da Lei $\mathrm{n}^{\circ} 13.005$, de 25 de junho de 2014, que instituiu o Plano Nacional de Educação (2014-2024), para um cenário de obscuro, possivelmente o pior golpe da sua limitada existência democrática desde a Constituição Federal de 1988? Caracterizar um movimento de retrocesso desse tamanho é trabalho delicado, dado todos os seus condicionantes, suas causalidades e possíveis interpretações. Algo dessa natureza não pode ter apenas uma única motivação. De fato, estão em jogo diversos fatores que concorrem para explicar a derrocada do setor e a contingência das expectativas experimentadas durante essa primeira quinzena de século, já que a prevalência de manobras fiscais desastrosas e erros políticos consecutivos nos trouxeram a uma situação de agonia e desmonte da educação básica pública no Brasil.

Do ponto de vista econômico, as condições favoráveis observadas entre 2004 e 2010 criaram um contexto positivo para as políticas sociais, sendo que "o investimento cresceu em média 6,7\% ao ano no período" (CARVALHO, 2018, p. 10), contribuindo para a consolidação de uma importante série histórica de caráter expansionista dos gastos específicos com a educação pública. Contudo, tal rompante foi sendo relativizado pela agenda governamental adotada entre 2011 e 2014, para finalmente ser desconstruído desde o plano de ajuste fiscal de curto prazo colocado em prática em 2015, fato que impactou imediatamente nas dotações autorizadas para o setor (ROSSI; OLIVEIRA; ARANTES, 2017). Por essa razão, é que para alguns dos analistas que acompanham de perto a temática do financiamento, tal momento 
de êxito não passara de uma cortina de fumaça que fez mais uma vez obnubilar a persistente crise do financiamento da educação pública no Brasil. (MONLEVADE, 2014).

Já do ponto de vista político, as críticas são ainda mais severas, haja vista a sucessão de erros acumulados que fizeram recrudescer a ideia de que a onipresença do Estado - mas não só - seria a causa dos gastos exagerados e ineficientes com educação pública, especialmente com o ensino superior, o que justificaria por si só o retorno às soluções caseiras bastante conhecidas por todos nós desde os anos 1990. Claro, agora acrescidas de rearranjos estruturais e rejuvenescidas pela entrada de novos agentes, muitos deles postulantes de uma reconversão ideológica do terreno onde se opera atualmente a educação nacional. Quer dizer, pari passu a generalizada crise política ganhou substância uma representação sobre educação pública que se apresenta como uma proposta de transformação radical moldada profundamente por um discurso de modernização que esconde um retrocesso, caraterística e risco, daquilo que se tem chamado de "conservadorismo liberal ou liberalismo conservador" (CAVALCANTE, 2015, p. 192).

Em geral, pode ser que a compreensão dessa crise educacional ainda divida entendimentos que variam entre sorte e azar macroeconômicos ou entre acertos e erros na implementação de políticas públicas. Mas, a despeito de divergências mais fugazes, é preciso sempre localizar o problema do subdimensionamento do gasto educacional, pois persiste um grave problema de interpretação entre o que é efeito e o que é causa da crise, já que, acima de tudo, podemos considerar que temos um "problema sócio-político de distribuição e não apenas um problema estritamente econômico de contabilidade social” (BLYTH, 2017, p. 22). Por essa e outras razões é que emergiram tantas críticas à constitucionalização de um ajuste fiscal pela via da Emenda 95/2016. 0 fato é que após um período de estabilidade econômica, o Brasil enfrenta novamente dificuldades para lidar com as despesas e os investimentos públicos em serviços essenciais, já que nos últimos anos apostaram-se nas desonerações fiscais e na concessão de subsídios a fim de fortalecer o mercado como motor do crescimento e investidor em infraestrutura, mas o dinheiro não voltou, ocasionando o aumento do desemprego e piorando muito a situação das contas públicas e da economia nacional.

Nesse contexto de caos instaurado pelas contradições inerentes à crise econômica e política foi que o Banco Mundial entregou o relatório intitulado Um ajuste justo: análise da eficiência e equidade do gasto público no Brasil (2017) ${ }^{2}$, encomendado junto ao Grupo Banco Mundial pelo ex-ministro da Fazenda do governo Dilma Rousseff (PT), Joaquim Levy, e apresentado aos ministros do governo de Michel Temer (MDB), Henrique Meirelles (Fazenda) e Dyogo Oliveira (Planejamento), em novembro de 2017. A análise que vamos apresentar tem como objeto a compreensão crítica das nuances contidas nesse relatório do Banco Mundial, especificamente da seção acerca da situação da educação básica do país, em que se vê a sugestão de um rol de proposições para se "economizar parte do orçamento sem prejudicar o acesso e a qualidade dos serviços públicos” (BANCO MUNDIAL, 2017, p. 01). Alega-se que a superação do crescimento do PIB pelo crescimento das despesas

\footnotetext{
2- 0 relatório foi confeccionado por uma equipe do Banco Mundial chefiada por Antonio Nucifora, Cornelius Fleischhaker e Fritzi KoehlerGeib, sob a orientação de Martin Raiser e Pablo Saavedra. Contou ainda com a colaboração de vários especialistas e acadêmicos Brasileiros e internacionais, como Andre Portela, Daniel Santin, Eduardo Pontual Ribeiro, Gabriel Ulyssea, Justin Barnes, Leonardo Lima Chagas, Stephen O’Connell, Ricardo Pais de Barros, Sergio Perelman, Stella Lobo e Tim Sturgeon.
} 
primárias tornou o gasto público incontrolável, dificultando o equilíbrio das contas e a execução de novos investimentos.

A ideia é que o aumento dos investimentos públicos no contexto de rigidez constitucional e queda da arrecadação tem sido responsável por "déficits fiscais anuais superiores a 8\% do PIB, em 2015 e 2016, e aumento da dívida pública de 51,5\% do PIB (2012) para mais de 73\% do PIB (2017)" (BANCO MUNDIAL, 2017, p. 07). No caso da educação básica pública, objeto deste trabalho, interessa-nos saber se isso é factível considerando nosso contexto histórico de subfinanciamento, onde diferentemente de outros países mais ricos e menos desiguais, jamais alcançamos um patamar adequado para garantir o mínimo de qualidade. Quer dizer, quais são as chances reais de que uma tendência deslizante de investimentos traga melhor qualidade e fortaleça o direto à educação?

\section{Aspectos metodológicos}

Em vista do objetivo do trabalho e dada a amplitude e complexidade do relatório, fizemos uma análise documental centrada nas principais ideias sobre a educação básica pública expressas na seção Gastar mais ou melhor? Eficiência e equidade da educação pública. A interpretação de tais ideias resultaram em quatro eixos de discussão: 1) os pontos de incidência do ajuste fiscal pelo Banco Mundial; 2) as suas possíveis consequências para a educação básica; 3) o questionamento da ideia de eficiência apresentada como salvação para todos os males econômicos; e 4) a crítica à austeridade como medida satisfatória em um contexto histórico de subfinanciamento.

A partir das informações coletadas na imprensa e das referências bibliográficas pertinentes ao campo do financiamento educacional, os eixos entrelaçaram-se ao longo da narrativa de modo a construir e demonstrar uma visão crítica do documento analisado coerente com a epistemologia do trabalho. Com o emprego de técnicas simples de análise de conteúdo buscou-se não só desvelar os sentidos e métodos presentes no relatório, mas também suas conotações políticas mais latentes, já que apesar da tecnicidade o texto não omite o posicionamento do ideológico do Banco Mundial.

\section{O ajuste justo e a panaceia da eficiência}

0 relatório apresenta algumas análises sobre os gastos públicos brasileiros em áreas distintas do Estado, sempre apontando para soluções orçamentárias voltadas para a sustentabilidade fiscal dos três entes federativos. Verifica-se, de acordo com o Quadro 01, que entre as proposições para o ajuste se encontram medidas como: a redução salarial do funcionalismo público, políticas de accountability, bonificações seletivas e escalonadas, emprego de novos métodos e estratégias customizadas para licitações públicas, a institucionalização de novas formas de controle e avaliação das políticas públicas, dentre outras. 0 estudo identifica "pelo menos 7\% do PIB em potenciais economias fiscais em nível federal até 2026" (BANCO MUNDIAL, 2017, p. 14), com destaque para as projeções feitas para a reforma da previdência $(1,8 \%)$, as mudanças em programas de assistência social e de apoio ao mercado de trabalho $(1,3 \%)$, a redução nos créditos subsidiados e nos gastos tributários de apoio às empresas (2,0\%) e as reformas nos setores da saúde e educação $(1,3 \%)$. 


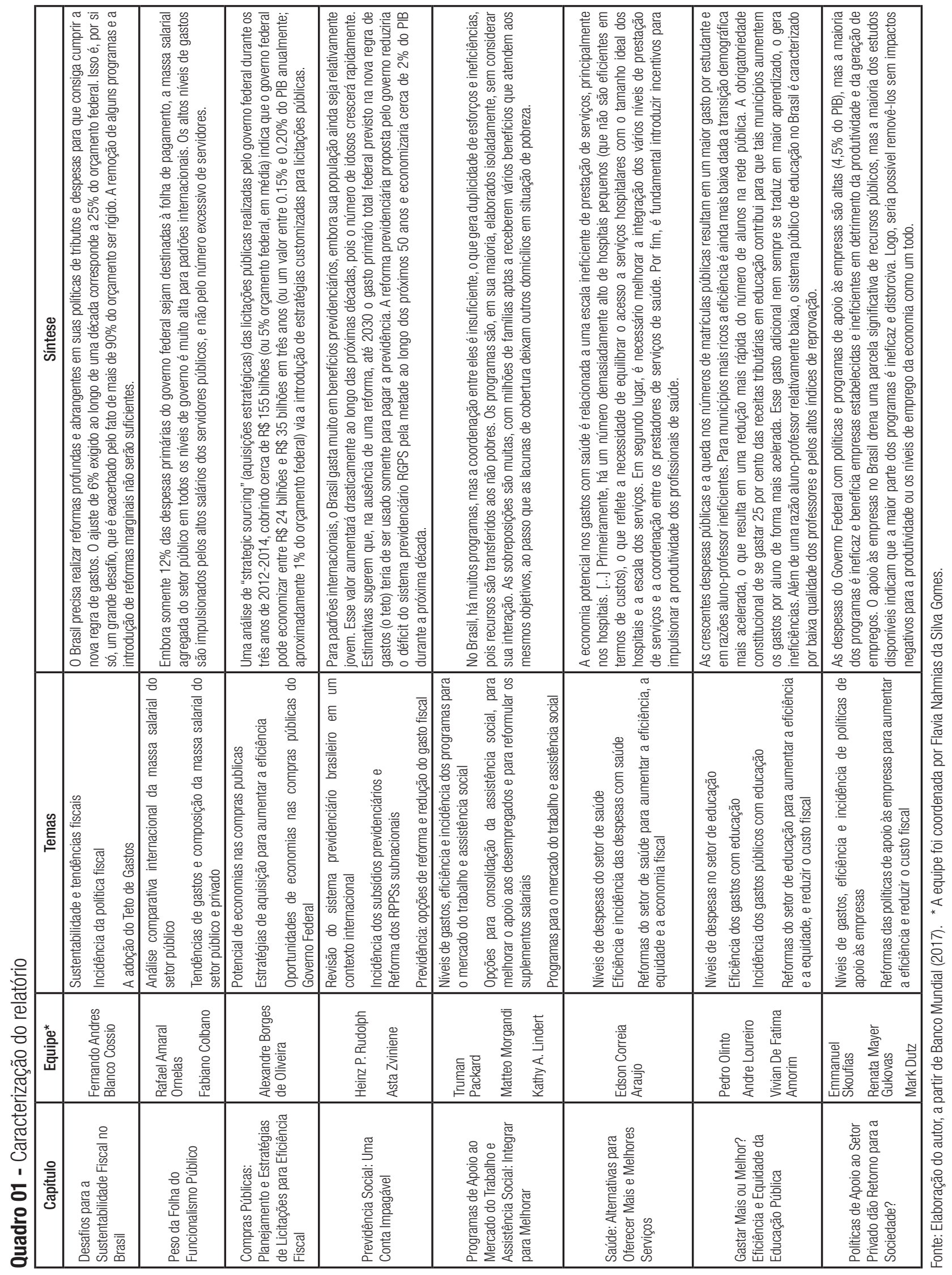


Cabe ressaltar, que mesmo apresentando uma retórica mais preocupada com os impactos sociais oriundos das medidas que contemplam o ajuste fiscal sugerido, trata-se da indicação do mesmo remédio amargo de sempre, ou seja, ratifica-se a concepção mais recorrente nas orientações do Banco Mundial, em que comumente se leem os objetivos de reestruturação do Estado e de salvação econômica via diminuição da dívida e aumento da poupança interna por meio de redução dos gastos públicos e demais reformas e medidas quase sempre impopulares. Uma das hipóteses do Banco Mundial (2017, p. 07) é que "ao longo das duas últimas décadas, o Brasil observou um consistente aumento dos gastos públicos, o que agora coloca em risco a sustentabilidade fiscal", e por isso diz em tom de ameaça que se a crise fiscal não for revertida os resultados poderão nos fazer reviver os tempos críticos dos anos 1980 e 1990, com a volta da inflação e a desvalorização cambial. Logo no Prefácio do relatório lê-se o seguinte:

Após um período de estabilidade econômica, altas taxas de crescimento e redução substancial da pobreza, o Brasil enfrenta hoje grandes desafios para lidar com seus gastos públicos. 0 crescimento das despesas primárias superou o PIB mesmo durante a fase favorável do super ciclo das commodities. 0 gasto tornou-se cada vez mais engessado pela rigidez constitucional em categorias como folha de pagamento e previdência social, deixando quase nenhum espaço para despesas discricionárias e de investimento. (BANCO MUNDIAL, 2017, p. 01).

No sentido de apontar os caminhos para a superação dos desafios que concernem à sustentabilidade fiscal no país, o Banco Mundial dispara mais uma vez suas análises na direção as cinco áreas problemáticas da gestão púbica, sendo elas: a folha salarial do funcionalismo, as compras e licitações públicas, o déficit da previdência social, os programas de assistência, saúde, educação e as políticas de apoio ao empresariado. Sem titubear, o argumento central constrói-se em cima da tese bastante conhecida de que "os excessos passados - de gastos sociais, de aumento de salário mínimo, de intervencionismo estatal - estão cobrando os sacrifícios atuais" (DWECK et al., 2018, p. 03). Isto é, admitese que somente um extenso ajuste nos gastos do governo federal poderia produzir as externalidades positivas almejadas, satisfazendo as demandas fiscais, o crescimento econômico e melhorando a confiança dos investidores ${ }^{3}$.

\begin{abstract}
Nos últimos anos, o impacto do aumento constante dos gastos foi agravado pela queda das receitas resultante de uma profunda recessão e pelo crescimento dos gastos tributários. Essa combinação resultou em défıcits fiscais anuais superiores a 8\% do PIB em 2015-2016 e um aumento da dívida pública de 51,5\% do PIB em 2012 para mais de 73\% do PIB em 2017. 0 ajuste fiscal necessário para estabilizar a dívida pública no médio prazo é grande - cerca de $5 \%$ do PIB no resultado primário. (BANCO MUNDIAL, 2017, p. 07).
\end{abstract}

\footnotetext{
3 - Mesmo que haja um descompasso entre arrecadação e despesas, como demonstram os dados do Sistema Integrado de Administração Financeira do Governo Federal (SIAFI) - a soma dos valores nominais, em Real, das despesas correntes e de capital passou de 588.535.656.712,71, em 1999, para 2.714.008.533.883 em 2018 - a saída passa menos por cortes e contingenciamentos, como propõe o Banco Mundial, e mais por soluções como a recuperação de uma agenda de reforma tributária focada na progressividade, como defendem Orair; Gobetti (2016), apostando na tributação do excedente de lucros e dividendos distribuídos.
} 
Segundo Dweck et al. (2018), desde o início da crise econômica, a política de austeridade fiscal tem sido colocada como um novo pacto social, representativo de um país cuja democracia declina e a participação do Estado na economia está cada vez mais contestada, condições que se materializam na redução dos recursos públicos para a garantia dos direitos sociais. 0 que se está propondo é o ajuste das finanças a partir da contração da participação do Estado na economia, que se materializa em perdas orçamentárias, principalmente para os serviços e direitos essenciais. Em síntese, essa proposta de regime fiscal pretende conter o crescimento real das despesas do governo federal a fim de reduzir o gasto público per capita, e por isso, a opção por esse plano de ajuste estrutural parece cronicamente inviável, já que apregoa a imposição de um regime fiscal duríssimo para as despesas primárias como forma de acelerar a economia e conter a dívida pública, ainda que não haja evidências suficientes sobre esses efeitos.

Ao longo de suas 156 páginas, o relatório do Banco Mundial ratifica a tese de que a falta de eficiência dos gastos brasileiros se dá mais pela péssima gestão pública do que por problemas estruturais ligados à falta de investimentos adequados, por exemplo. Quer dizer, apostam em uma ideia que não encontra respaldo na evidência empírica e que escamoteia sua verdadeira intenção, que é corroborar como o aprofundamento do neoliberalismo no país. A todo momento o texto reafirma o compromisso do Banco Mundial com a criação de condicionalidades macroeconômicas e a definição de diretrizes setoriais para suas experiências de modernização. Ao analisar o conjunto da obra, fica evidente que com a posição assumida, mais favorável à desestatização e a constrição dos investimentos públicos, busca-se de todas as formas sacralizar a ideia, que não é nova, de que o governo brasileiro estaria gastando mais do que pode com os serviços relacionados com as políticas sociais em geral. Além disso, enfatiza-se a concepção segundo a qual ao aplicar mal os recursos disponíveis estaria inviabilizando ou contribuindo pouco para o crescimento econômico.

Existe no discurso do Banco Mundial a prevalência por soluções que desprezam os direitos sociais em favor da eficiência econômica e dos resultados. 0 problema é que mesmo admitindo que "o teto não garante a qualidade do ajuste fiscal" (BANCO MUNDIAL, 2017, p. 18), a análise desenrola-se sempre na direção do questionamento de aspectos orçamentários tidos como decisivos para a ineficiência dos gastos públicos. Esta é a hipótese e a conclusão de um relatório cercado de controvérsias, não há dúvida. A retórica da austeridade continua a dominar o receituário e o pressuposto é o de que a contração do gasto público permitiria em tese um espaço mais dinâmico para a expansão do setor privado e seus possíveis investimentos. É a ideia problemática de que "os investimentos das empresas podem funcionar como motor autônomo de retomada em meia à recessão e ao alto endividamento" (CARVALHO, 2018, p. 166), mesmo com toda a literatura crítica que expõem as fraturas desse tipo de política fiscal (DARDOT; LAVAL, 2014; BLYTH, 2017; LEBARON, 2018; BROWN, 2018). 


\section{As recomendações para a educação básica}

No que concerne ao debate acerca da educação pública, sabemos que a cooperação técnica e financeira do Banco Mundial ao setor não é recente, ao contrário, remete aos anos 1970. Desde então o mesmo vem influenciando governos e políticas públicas ao defender "explicitamente a vinculação entre educação e produtividade, a partir de uma visão economicista” (ALTMANN, 2002, p. 83). Evidencia-se que o grau de impacto de suas análises e orientações vem ganhando proeminência a cada novo ciclo de ajustes neoliberais promovido no Brasil, sobretudo, pela promessa de que os ajustes poderiam tornar o país cada vez mais competitivo no mercado internacional. 0 cenário atual consolidado pelo novo regime fiscal imposto pela EC 95/16, que congelou o gasto federal com educação no patamar real estabelecido pelos valores mínimos do ano de 2017, criou precedente para a atuação do Banco, já que ao legitimar o subfinanciamento característico da educação nacional, abriram-se novos caminhos para a privatização do setor. 0 excerto abaixo sintetiza as principais preocupações levantadas pela análise empreendida pelo Banco:

As crescentes despesas públicas e a queda nos números de matrículas públicas resultam em um maior gasto por estudante e em razões aluno-professor ineficientes. Para municípios mais ricos a eficiência é ainda mais baixa dada a transição demográfica mais acelerada, o que resulta em uma redução mais rápida do número de alunos na rede pública. A obrigatoriedade constitucional de se gastar 25 por cento das receitas tributárias em educação contribui para que tais municípios aumentem os gastos por aluno de forma mais acelerada. Esse gasto adicional nem sempre se traduz em maior aprendizado, o gera ineficiências. Além de uma razão aluno-professor relativamente baixa, o sistema público de educação no Brasil é caracterizado por baixa qualidade dos professores e pelos altos índices de reprovação. Todos esses fatores levam a ineficiências significativas. (BANCO MUNDIAL, 2017, p. 121).

0 documento propõe algumas ações que poderiam remediar em médio prazo as consequências das duas situações supracitadas, são elas: a) Permitir o aumento da razão aluno-professor nas escolas mais ineficientes para, gradualmente, chegar a níveis de eficiência por meio da não reposição dos professores que se aposentarem; b) Limitar a contratação de novos professores concursados, cuja demissão é extremamente difícil e cujos custos são significativos, uma vez que eles se aposentam cedo com vencimentos integrais; c) Nomear diretores escolares com base em seu desempenho e experiência; d) Fazer os professores dedicarem mais tempo às atividades em sala de aula e reduzindo o absenteísmo; e) Pagar bônus aos professores e funcionários com base no desempenho das escolas; f) Destacar as escolas com desempenho melhor; g) Contratar empresas privadas para fornecer serviços de educação; h) Apostar nas escolas charter; e i) Aprovar novas leis federais, estaduais e municipais para permitir PPP na Educação Básica.

Ao questionar se o Brasil deveria gastar mais ou melhor com a educação pública, o relatório apresenta alguns argumentos para problematizar a tese de que a péssima 
situação contábil da educação brasileira é justificada pelas crescentes despesas públicas somadas à queda nos números de matrículas, que resultaram em um "maior gasto por estudante e em razões aluno-professor ineficientes” (BANCO MUNDIAL, 2017, p. 121). Acredita-se que a:

[...] ineficiência dos ensinos fundamental e médio está principalmente relacionada ao número excessivo de professores. Aproximadamente 39\% da ineficiência dos gastos brasileiros com educação estão associados às baixas razões aluno-professor. (BANCO MUNDIAL, 2017, p. 129).

Assim, a solução passaria pelo o aumento dessa razão, especificamente, 33\% para o Ensino Fundamental e 41\% paro o Ensino Médio, capilarizando uma possível economia de 0,3\% do PIB, o equivalente a R 22 bilhões por ano, segundo as contas do Banco. Para alcançar tal razão, a estratégia proposta passa pela não reposição dos professores que se aposentarão em breve e com a quebra da estabilidade do funcionalismo. Contudo, tal discussão do relatório acerca da baixa razão professoraluno contradiz os dados de outra publicação recente, o estudo da Organização para a Cooperação e Desenvolvimento Econômico (OCDE), Education at a glance (2017), que revela a persistência de uma razão aluno-professor alta (Figuras 1 e 2) e a inadequação da despesa por estudante, ainda muito abaixo da média dos países da OCDE (Gráfico 1).

Figura 1 - Tamanho médio das turmas nas instituições de ensino, por nível de educação (2015)

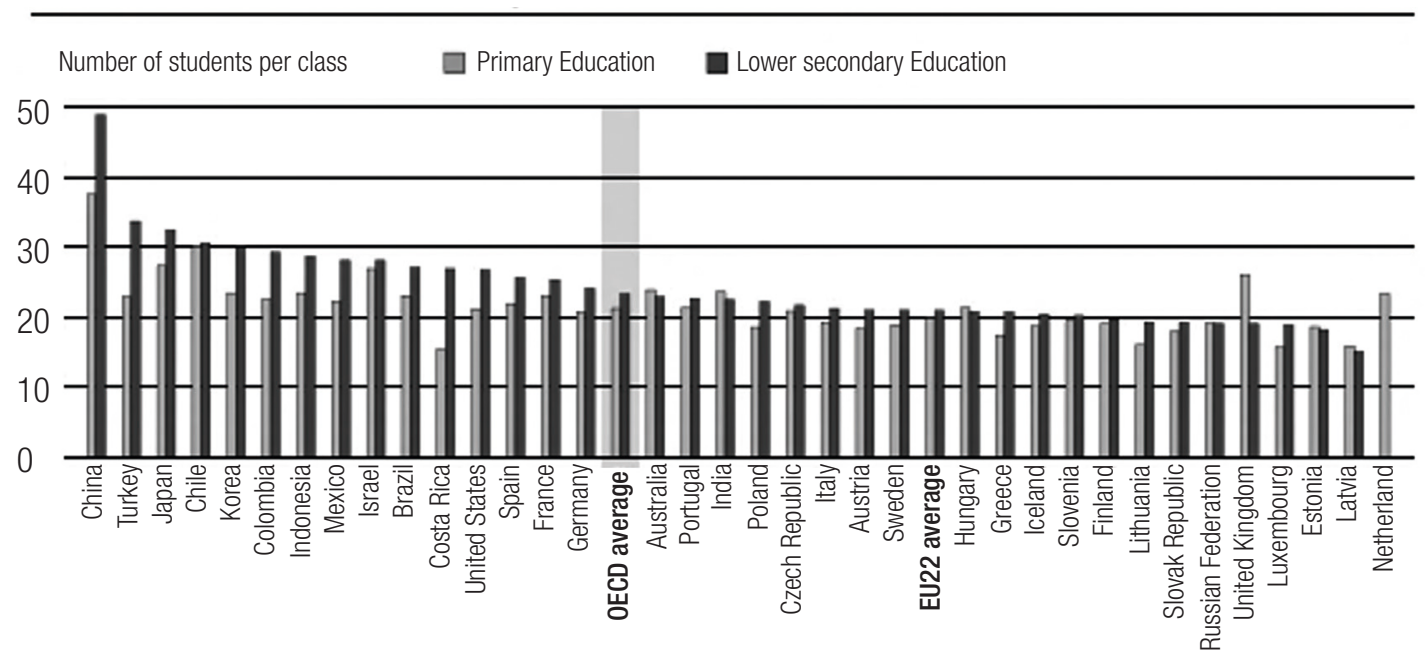

Fonte: Education at a glance (OCDE, 2017). 
Figura 2 - Número de professores por sala (2015)

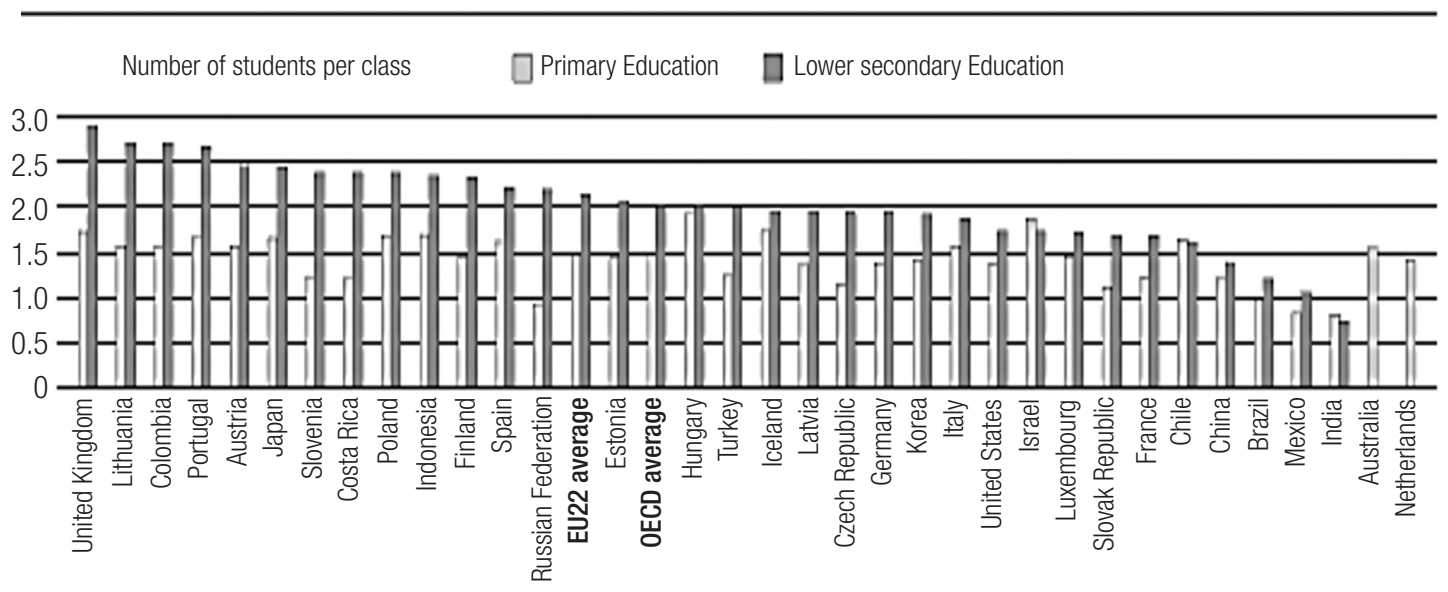

Fonte: Education at a glance (OCDE. 2017.

Gráfico 1 - Gasto anual por estudante, por etapa, 2014 (em Dólar PCC) ${ }^{4}$

Ensino Fundamental ao Superior

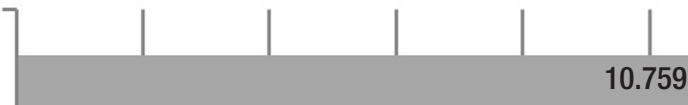

Ensino Fundamental (Anos finais) e Ensino Médio

Ensino Superior
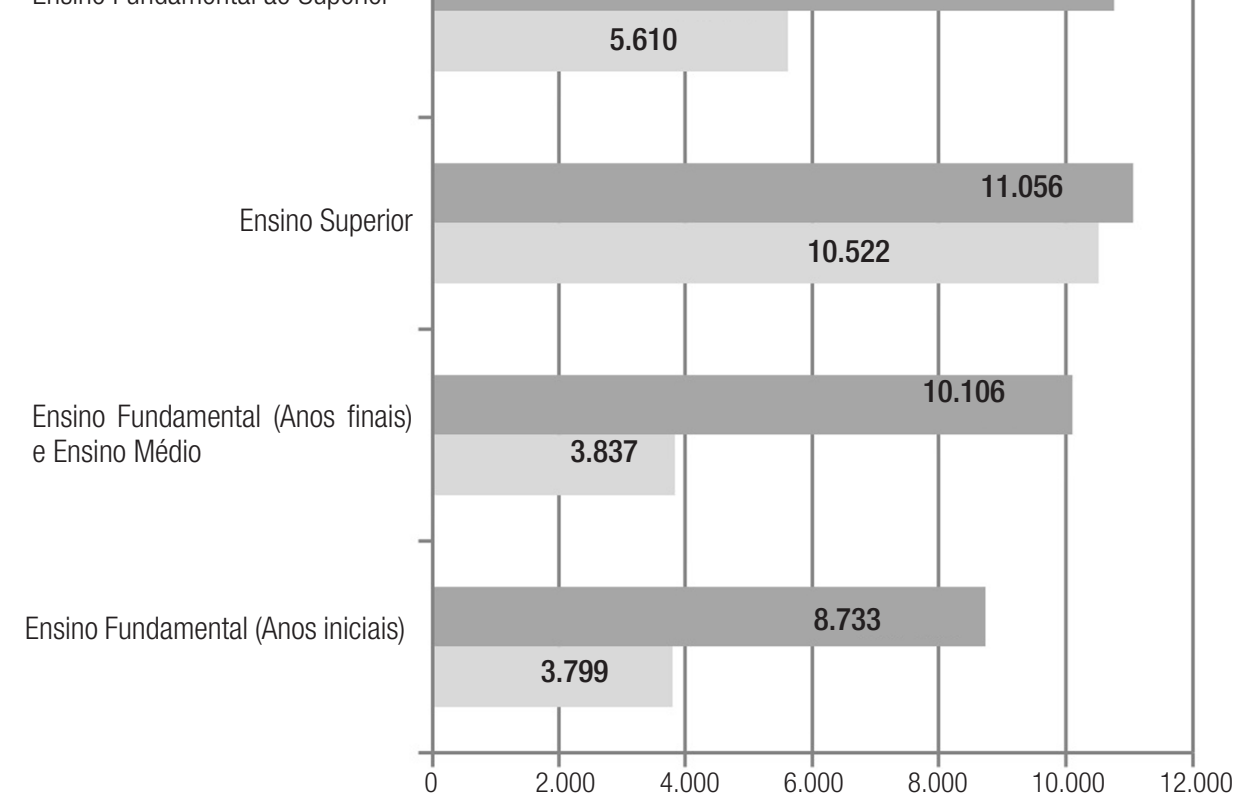

Fonte: Elaboração do autor, a partir de Education at a Glance (2017).

4- Cabe ressaltar que os valores nominais apresentados no estudo da OCDE são calculados pela paridade do poder de compra (PPC) do Dólar americano. Isso indica a necessidade de relativizá-los também em relação ao PIB per capita do nosso país, já que medir o padrão de investimentos apenas com o modelo de PCC quanto com a taxa de câmbio pode gerar imprecisão. São conhecidas as realidades de países cujos investimentos por aluno em Dólar PCC estão abaixo daqueles dos países da OCDE, mas que têm bons sistemas de ensino e resultados educacionais satisfatórios, o que indica que cada sistema de ensino deve constituir razões próprias de custo e qualidade. 
Sobre os gastos por estudante, podemos ressaltar ainda que os mesmos permanecem muito aquém dos números projetados pelos mecanismos Custo-Aluno Qualidade Inicial (CAQi) e Custo-Aluno Qualidade (CAQ), que foram criados justamente para que as escolas públicas brasileiras sejam capazes de criar as condições necessárias para alcançarmos padrões mínimos de qualidade do ensino, conforme o estabelecido na Meta 20 do Plano Nacional de Educação (2014-2024), especificamente, nas estratégias 20.6, 20.7, 20.8 e 20.10.

Nesse contexto, mesmo considerando possíveis melhorias na gestão e somadas às questões demográficas indicadas pelo Banco Mundial, não há espaço para a economia de quase 1\% do PIB advogada. Segundo balanço recente divulgado pela Campanha Nacional pelo Direito à Educação ${ }^{5}$, considerando o orçamento público federal de 2018, a efetivação do CAQi custaria cerca de 0,15\% do mesmo, aproximadamente, $\mathrm{R} \$ 50$ bilhões a mais do que o previsto. A Tabela abaixo traz uma projeção dos valores a se alcançar para as escolas de Educação Básica nas áreas urbanas e rurais, o que representaria na prática quase cinco vezes mais do que é aplicado atualmente.

Tabela 1 - CAQi e CAQ para a Educação Básica, 2018 (em R\$)

\begin{tabular}{|c|c|c|c|c|}
\hline Etapa de ensino & $\begin{array}{l}\text { Jornada semanal } \\
\text { dos alunos }\end{array}$ & $\begin{array}{l}\text { Número de alunos por } \\
\text { turma }\end{array}$ & CAQi & CAQ \\
\hline Creche (tempo parcial) & $25 \mathrm{~h}$ & 11,2 & $12.307,11$ & $20.122,60$ \\
\hline Creche (tempo integral) & $50 \mathrm{~h}$ & 11,2 & $23.579,62$ & $39.210,61$ \\
\hline Creche + Pré-escola (campo) & $50 / 25 h$ & $10 / 15$ & $24.112,34$ & $38.168,36$ \\
\hline Pré-escola (tempo parcial) & $25 \mathrm{~h}$ & 20 & $9.607,02$ & $14.506,65$ \\
\hline Pré-escola (tempo integral) & $35 \mathrm{~h}$ & 20 & $14.457,21$ & $21.693,14$ \\
\hline Ensino Fundamental 1 (tempo parcial) & $25 \mathrm{~h}$ & 25 & $7.545,06$ & $11.152,81$ \\
\hline Ensino Fundamental 1 (tempo integral) & $35 \mathrm{~h}$ & 25 & $10.932,65$ & $16.069,55$ \\
\hline Ensino Fundamental 1 (campo) & $25 \mathrm{~h}$ & 16 & $15.089,80$ & $18.165,01$ \\
\hline Ensino Fundamental 2 (tempo parcial) & $25 \mathrm{~h}$ & 30 & $6.604,99$ & $9.082,02$ \\
\hline Ensino Fundamental 2 (tempo integral) & $35 h$ & 30 & $10.609,11$ & $14.765,57$ \\
\hline Ensino Fundamental 2 (campo) & $25 \mathrm{~h}$ & 20 & $10.879,12$ & $15.835,94$ \\
\hline Ensino Médio (tempo parcial) & $25 \mathrm{~h}$ & 35 & $5.454,74$ & $7.369,09$ \\
\hline Ensino Médio (tempo integral) & $35 h$ & 35 & $8.293,19$ & $11.428,60$ \\
\hline Ensino Médio (campo) & $25 \mathrm{~h}$ & 24 & $9.100,35$ & $12.816,23$ \\
\hline EJA & $25 \mathrm{~h}$ & 22 & $9.049,68$ & $13.062,99$ \\
\hline Educação Especial e Inclusiva & $25 \mathrm{~h}$ & - & $19.167,47$ & $28.965,48$ \\
\hline
\end{tabular}

Fonte: Campanha Nacional pelo Direito à Educação, 2018.

5- Disponível em: http://campanha.org.br/plano-nacional-de-educacao/depois-de-4-anos-de-vigencia-do-plano-nacional-de-educacaodentre-os-dispositivos-com-prazo-entre-2014-e-2018-somente-um-foi-cumprido-integralmente-e-30-parcialmente/. Acesso em: 17 set. 2018. 
Outro aspecto destacado pelo relatório do Banco Mundial é que a baixa qualidade dos professores seria o principal fator restringindo a qualidade da educação e que:

[...] os requisitos para ingresso em cursos de licenciatura são fracos e a formação é de baixa qualidade. E além da pouca seletividade na contratação de professores para os sistemas educacionais estaduais e municipais, os salários não são vinculados do desempenho. (BANCO MUNDIAL, 2017, p. 127).

Acerca disso, longe de menosprezar os problemas existentes na formação dos professores, entendemos que tal assertiva favorece e perpetua a desvalorização do magistério público ao escamotear sua real condição em termos de condições de trabalho e suas perdas salariais. Ademais, diante dos problemas já conhecidos da educação básica pública no Brasil, não nos parece politicamente correto e factível concluir que os problemas nos ensinos fundamental e médio se devem, sobretudo, pela má qualidade dos professores. Para endossar a argumentação, recorremos outra vez aos dados da publicação Education at glance (2017, p. 364), onde se lê que os salários mínimos pagos por instituições públicas de educação básica no Brasil variam para menos de 15 mil dólares anuais (PPC), bem abaixo da média da OCDE.

Por fim, o documento ainda questiona o número excessivo de professores e suas condições de contratação, planos de carreira e regime previdenciário. 0 relatório afirma que o salário dos professores brasileiros é competitivo se comparado aos países com renda per capita similar e que seus planos de carreira favorecem o rápido aumento dos ganhos. Destacase ainda "que os professores brasileiros têm direito a planos previdenciários relativamente generosos quando comparado a outros países da OCDE” (BANCO MUNDIAL, 2017, p. 127). Nesse caso, mais um ponto polêmico do relatório, isso porque negligencia o Artigo 206 da Constituição Federal (BRASIL, 1988), onde se expressa a preocupação republicana com a valorização adequada do magistério em termos de salário e carreira e ainda inviabiliza o cumprimento da Meta 17 do PNE que versa sobre a equiparação dos rendimentos dos profissionais do magistério ao dos demais profissionais com escolaridade equivalente.

0 documento do Banco Mundial faz isso, não obstante toda a realidade encontrada por muitas pesquisas científicas/acadêmicas, cujos resultados apontam que os professores brasileiros da educação básica pública em média ganham salários mais baixos que outros profissionais do setor privado com formação equivalente (defasagem em torno de 30\%) e que sua jornada de trabalho mais comum é a de 40 horas semanais (ALVES; PINTO, 2011; BARBOSA, 2014; JACOMINI; ALVES; CAMARG0, 2015). Por essa razão, dizer que o piso salarial dos professores brasileiros está alinhado como o que se paga em outros países estruturalmente comparáveis não significa que o trabalho docente seja valorizado por aqui, pois, na maioria dos países, inclusive os da OCDE, mantém-se a mesma desigualdade salarial entre trabalhadores com formação equivalente. Além do que, não enfrenta o problema das jornadas extensivas e das péssimas condições de trabalho na maioria das escolas.

Em suma, para os economistas do Banco aquilo que é essencial para a educação deve coincidir sempre com o equilíbrio das relações de custo-benefício e com as taxas de retorno, caso contrário, ela é onerosa. Por si só, tal argumento não é suficiente para justificar a redução dos investimentos, especialmente, porque nós não temos gastos 
acumulados no patamar mínimo por aluno, o que se traduz também nos desempenhos pouco expressivos nas avaliações em larga escala e no comprometimento da produtividade em geral (PINTO, 2014). Nesse caso, soa inflexivo correlacionar eficiência e desempenho, que são em boa medida fatores idiossincráticos, sem antes garantir um grau de insumos que gere qualidade.

Acreditam ainda que esse tipo "de perspectiva educacional vá criar oportunidades para que as pessoas pobres se desenvolvam, de modo que se alcance justiça social e estabilidade econômica” (ALTMANN, 2002, p. 86), o que é contraditório, pois, na prática, o que ela tem produzido é uma lógica que fortalece a má qualidade do ensino e as desigualdades sociais. Não há vacilação quando se trata de legitimar qualquer reorganização da educação básica que a favoreça como privilégio e que abra campo para a privatização dela. Por isso, o caso da educação é emblemático desse processo que tem nos conduzido ao aprofundamento de um "Estado de bem-estar empresarial” (CARVALHO, 2018, p. 157).

\section{Austeridade e manutenção do subfinanciamento}

A análise das proposições ofertadas pelo relatório do Banco Mundial revela-nos que dentre os vários desdobramentos da crise política e econômica que afeta a educação básica no Brasil, chama atenção o fato delas não abalarem, de modo muito público, certo proselitismo acerca da eficiência, taxas de retorno, dentre outras convicções presentes no texto. Afinal, trata-se do velho receituário que continua a condicionar as regras $d u$ jour por aqui, seja na agenda implementada nos governos trabalhistas do PT, na Ponte para o Futuro do PMDB e agora com Jair Bolsonaro. Ademais, a forma como os analistas do Banco Mundial apresentam os problemas condicionados pela realidade fiscal brasileira mais joga sombra sobre as dificuldades do que esclarece, por isso não aponta para uma saída mais razoável. 0 relatório faz uma análise viciada, que aposta na lógica de quanto mais dinheiro, menor a eficiência dos gastos, o que em nossa visão pode levar a um diagnóstico impreciso e que perpetua o subfinanciamento. A predominância dessa lógica fica explícita no excerto abaixo:

Municípios mais ricos, com uma alta taxa de receita corrente líquida por aluno, tendem a ser bem menos eficientes que municípios mais pobres. Logo, é provável que para cumprir as regras constitucionais, muitos municípios ricos sejam obrigados a gastar em itens que não necessariamente ampliem o aprendizado. [...] Se este gasto adicional por aluno não resulta em maior aprendizado, isso explicaria a maior ineficiência de municípios mais ricos. (BANCO MUNDIAL, 2017, p. 13).

O que se vê no documento é um esforço econométrico para justificar a inevitabilidade dos cortes e contingenciamentos para o setor educacional, sempre ressaltando a importância da interface com um amplo e rígido programa de controle fiscal, cuja meta seria economizar nos gastos com despesas primárias federais em proporção ao PIB a fim de restituir os níveis mais sustentáveis com as despesas. Contudo, tal esforço esgota-se e não oferece um horizonte de estratégias para a geração de novas receitas para a equiparação do CAQ e/ou uma nova dinâmica para melhorar a distribuição dos recursos existentes via 
Fundo de Manutenção e Desenvolvimento da Educação Básica (FUNDEB), por exemplo. É nesse sentido que Deirdre Mccoloskey (2017) questiona o discurso economicista e sua ambição incorrigível pela quantificação e pela significância estatística, por comumente apresentar soluções baseadas em pecados erroneamente identificados como virtudes.

Não se vê na análise uma explicação técnica mais ampla sobre, por exemplo, o porquê da queda do resultado primário nos últimos anos. Sabemos, pelos analistas, que foi muito mais por conta da diminuição da arrecadação do que por aumento das despesas. Suas contas não demonstram que a trajetória recente de aumento da dívida tem pouca relação com as despesas primárias (DWECK, 2018). Não falam a respeito dos impactos que a regressividade do nosso sistema tributário tem no financiamento público e nos investimentos em Manutenção e Desenvolvimento do Ensino. Comentase apenas superficialmente sobre os gastos com a dívida pública e suas implicações para o orçamento. Não esclarece que as contrações fiscais não produzem, geralmente, externalidades positivas, ao contrário, doutrina a economia à mercê da confiança dos agentes privados. E, por isso, cortar e contingenciar o orçamento coloca-se como a saída escolhida para controlar os gastos com educação básica.

$\mathrm{Na}$ melhor das hipóteses, o texto traz-nos uma mea verdade acerca da eficiência dos gastos, mas o faz escamoteando interesses que são políticos e ideológicos, pois sabe-se que seus efeitos incidem mais diretamente em determinados setores da sociedade e do Estado, particularmente, os estudantes, os trabalhadores da saúde e educação, os aposentados e pensionistas, os funcionários públicos do quadro burocrático, os beneficiários de programas sociais. Não há surpresa nisso haja vista que:

[...] a perda de empregos, terceirização, downsizing e reduções de benefícios, bem como os cortes em educação pública, infraestrutura e assistência social, todos são tomados como decisões econômicas pela governança neoliberal, e não como decisões políticas. (BROWN, 2018, p. 46).

No cerne da narrativa neoliberal, essas categorias citadas costumam ser mais culpabilizadas por onerar demais os cofres públicos. Segundo Rossi; Oliveira; Arantes (2017, p. 01) "a austeridade é sempre seletiva, pois prejudica principalmente os mais vulneráveis”. A situação agrava-se mais ao considerarmos o contexto de demandas ampliadas da população, especialmente, os mais pobres, devido ao aumento do desemprego, do endividamento e da diminuição da renda provocados pela recessão dos últimos anos. As recomendações de austeridade para a educação básica pública presentes no relatório acentuam o subfinanciamento e abrem uma janela de negócios para o mercado educacional, o que corrobora com a agenda do Banco Mundial, mais preocupada com o desmonte do nosso sempre combalido Estado e suas políticas sociais. Agora, é preciso dizer que além dos analistas mais heterodoxos, também dentro do próprio mainstream tem crescido a crítica a recomendações com essa radicalidade, devido aos seus efeitos duvidosos sobre a melhoria da gestão e da qualidade da educação.

A austeridade costuma não funcionar tal e qual seus defensores anteveem. Não há clareza e menos ainda certeza sobre registros positivos de consolidações fiscais expansionistas. Na maioria dos casos em que a austeridade foi colocada como saída 
verificaram-se indícios que nos levam a entender que tal remédio amargo costuma se traduzir em instabilidade política, no aumento do desemprego, na redução dos programas sociais, no maior endividamento da população e na queda da qualidade da educação.

Segundo Lebaron (2018), a austeridade é um conceito que envolve um amplo universo semântico, cujas implicações simbólicas e discursivas devem nos levar invariavelmente a interpretá-la como crença econômica e como discurso performativo. Mas, não é difícil de entender por que tal política penitencia a sociedade e produz tanto estrago por onde se aplica. Ao examinarmos a defesa da austeridade enquanto política econômica capaz de promover melhorias na oferta dos serviços e na qualidade de vida, percebemos que comumente seus custos sociais costumam ser maiores do que as melhorias corriqueiramente aventadas.

0 discurso encampado pelo Banco Mundial relaciona-se bem com uma visão de mundo específica que partilha de certa concepção de Estado e seu grau de intervenção nas sociedades capitalistas contemporâneas. Por isso, enganam-se aqueles que entendem que a política de austeridade fiscal é apenas um instrumento de controle dos gastos e da dívida pública, já que a experiência de alguns países europeus nos anos de 2010 e no Brasil desde 2015 demonstraram claramente que ela favorece a concentração de renda nas camadas mais altas da sociedade. Por isso, em tempos de crise, a aposta costuma ser essa, ao invés de se buscarem alternativas mais orgânicas de crescimento econômico e investimentos públicos. A história tem mostrado que os efeitos colaterais das políticas austeras começam a aparecer tão logo suas medidas são encampadas e que na maioria dos casos seus inconvenientes são remediados por meio da aplicação de novos gastos públicos e da criação de impostos ou do aumento da tributação já existente.

0 interesse na aplicação da austeridade é em parte ideológico, já que cria as condições para o encolhimento do Estado e a subtração das conquistas sociais, sendo que essas circunstâncias contribuem sobremaneira para a eliminação - prematura, em nosso caso - de alguns dos principais aspectos das formulações republicanas preocupadas com a promoção da cidadania, a educação básica, por exemplo, que no contexto recessivo e austero passa a ser conformada a partir da ideia do "sacrifício compartilhado" (BROWN, 2018 , p. 33). É a perseverança da ideia de que os ajustes são para o bem comum, que o aperto dos cintos, o enxugamento da máquina pública, a caça aos privilégios são essenciais para tirar o Estado do abismo e resgatar o crescimento econômico. Nesse sentido, a argumentação de Thomas Piketty (2014) em sua análise sobre o capital no século XXI ajuda-nos a questionar a necessidade da austeridade, haja vista a indicação feita por ele de que mesmo em contextos de crise econômica a taxa de rendimento real sobre o capital continua maior que a taxa de crescimento econômico. Em suma, a concentração de renda permanece contínua e inalterada.

É por isso que a austeridade "é melhor compreendida como uma opção de venda específica de classe” (BLYTH, 2017, p. 363). Sua defesa costuma escamotear os verdadeiros responsáveis pela crise econômica ao transferir o fardo para os cidadãos, sobretudo, aqueles que dependem do Estado para garantir seus meios de reprodução, já que em nome da retomada econômica esse cidadão "pode ser sacrificado às necessidades, vicissitudes e desigualdades do capital em seu posto de trabalho, nação ou constelação pós-nacional" (BROWN, 2018, p. 35). 0 uso do termo sacrifício por Wendy Brown é muito 
oportuno, pois denota com precisão o tipo de culpa e sofrimento subjetivo e material que envolve as pessoas em contexto de austeridade econômica. 0 convite à cidadania sacrificial está presente, agora mais do que nunca, nas narrativas ligadas à defesa dos cortes orçamentários, nas reorganizações dos serviços públicos, na revogação de direitos, no aumento da tributação e no sucateamento da educação básica.

Por fim, ressalta-se que para os analistas do Banco Mundial (2017, p. 121) "o Brasil está gastando 62\% mais do que precisaria para atingir o desempenho atualmente observado em escolas públicas, o que corresponde a quase 1\% do PIB". Portanto, os seus "elevados" gastos são um dos grandes problemas da falta de qualidade da educação, a ser recuperada com o equilíbrio fiscal proposto e não com a superação do subfinanciamento. Isto é, o texto agarra-se na ideia vulgar de que a crise educacional é produzida somente pela "má gestão" dos recursos humanos e financeiros por parte do Estado, ao que chamamos de panaceia da eficiência. 0 relatório admite que alcançar tal patamar de economia não será tarefa fácil, não sendo suficiente apenas "a remoção de alguns programas e a introdução de reformas marginais” (BANCO MUNDIAL, 2017, p. 21), mas, principalmente, o desenvolvimento de um plano abrangente para executar medidas que flexibilizem o orçamento ao restringir as vinculações constitucionais obrigatórias e alterem as condições previdenciárias vigentes. A justificativa é que isso poderia resolver o conflito distributivo que emerge do orçamento público federal, ainda que estudos recentes (COSTA; BASTOS; MESSENBERG, 2015; ROSSI; DWECK, 2016; CARVALHO, 2018) tenham mostrado que os cortes nos gatos públicos tendem a provocar o aumento na carga tributária, contração e recessão das economias, sobretudo, nos países em desenvolvimento.

\section{Considerações finais}

0 ajuste justo do Banco Mundial opera no sentido de fragilizar ainda mais o financiamento da educação básica, além de tangenciar em suas análises as dificuldades de se reestabelecer o estado democrático e público do sistema educacional ao fim de um longo ciclo de ajustes estruturais como os propostos. Nossa análise tentou evidenciar esse grave problema de calibragem do ajuste proposto e alguns dos seus problemas no desenho das estratégias para melhorar a gestão e a qualidade do ensino.

Concluímos dizendo que o relatório apresenta uma retórica aparentemente técnica, mas que na realidade faz a defesa - política, sem dúvidas - de uma agenda de austeridade fundamentada por um conjunto de dados que não correspondem às melhores práticas científicas e não avança de maneira responsável na direção de nortear os gastos de forma a promover inclusão e qualidade na educação básica pública. Em suma, estão mais preocupados em estimular mudanças fiscais sob o discurso de revisão da eficiência dos gastos do que considerar adequadamente o problema histórico do subfinanciamento. Por isso, suas propostas representam mais alguns passos atrás para educação básica pública no Brasil. 


\section{Referências}

ALTMANN, Helena. Influências do Banco Mundial no projeto educacional brasileiro. Educação e Pesquisa, São Paulo, v. 28, n. 1, p. 77-89, 2002.

ALVES, Thiago; PINTO, José Marcelino de Resende. Remuneração e características do trabalho docente no Brasil: um aporte. Cadernos de Pesquisa, São Paulo, v. 41, n. 143, p. 606-639, 2011.

BANCO MUNDIAL. Um ajuste justo: análise da eficiência e equidade do gasto público no Brasil: v. 1. [S. I.]: Banco Mundial, 2017. Síntese.

BARBOSA, Andressa. Salários docentes, financiamento e qualidade da educação no Brasil. Educação \& Realidade, Porto Alegre, v. 39, n. 2, p. 511-532, abr./jun. 2014.

BLYTH, Mark. Austeridade: a história de uma ideia perigosa. Tradução de Freitas e Silva. São Paulo: Autonomia Literária, 2017.

BRASIL. Constituição da República Federativa do Brasil de 1988. Brasília, DF: Presidência da República, 2016. Disponível em: http://www.planalto.gov.br/ccivil_03/Constituicao/Constituiçao. Acesso em: 08 set. 2020.

BROWN, Wendy. Cidadania sacrificial: neoliberalismo, capital humano e políticas de austeridade. Tradução de Juliane Bianchi Leão. Rio de janeiro: Zazie, 2018. (Pequena biblioteca de ensaios).

CARVALHO, Laura. Valsa brasileira: do boom ao caos econômico. 1.ed. São Paulo: Todavia, 2018.

CAVALCANTE, Sávio Machado. Classe média e conservadorismo liberal. In: VELASCO E CRUZ, Sebastião; KAYSEL, André; CODAS, Gustavo. Direita, volver! 0 retorno da direita e o ciclo político brasileiro. São Paulo: Fundação Perseu Abramo, 2015. p. 177-196.

COSTA, Fernando Nogueira da; BASTOS, Carlos Pinkusfeld; MESSENBERG, Roberto Pires. Políticas de austeridade econômica: 0 debate sobre alternativas. Revista Política Social e Desenvolvimento, São Paulo, v. 3, n. 16, p. 6-31, mar. 2015.

DARDOT, Pierre; LAVAL, Cristhian. A nova razão do mundo: ensaio sobre a sociedade neoliberal. Tradução de Mariana Echalar. São Paulo: Boitempo, 2016.

DWECK, Esther. As falácias do relatório sobre sustentabilidade fiscal e distribuição de renda. Carta Maior, São Bento, 19 dez. 2017.

DWECK, Esther et al. Impacto da austeridade sobre o crescimento e a desigualdade no Brasil. In: ENCONTRO NACIONAL DE ECONOMIA POLÍTICA, 23., 2018, Niterói. Anais... Niterói: [s. n.], 2018. p. 1-17. Meio digital.

JACOMINI, Márcia; ALVES, Thiago; CAMARGO, Rubens Barbosa. Plano Nacional de Educação e Remuneração Docente: desafios para o monitoramento da valorização profissional no contexto da meta 17. In: REUNIÃO NACIONAL DA ANPED, 37., 2015, Florianópolis. Anais... Florianópolis: UFSC, 2015. Documento digital. 
LAVAL, Cristhian. A escola não é uma empresa: o neo-liberalismo em ataque ao ensino público. Tradução Maria Luiza M. de Carvalho e Silva. Londrina: Planta, 2004.

LEBARON, Frédéric. Sociologia e ciências sociais em tempos de austeridade. Revista Sociedade e Estado, Brasília, DF, v. 33, n. 2, p. 529-537, 2018. DOl: https://doi.org/10.1590/s0102-699220183302012

MACLOSKEY, Deirdre. Os pecados secretos da economia. Tradução de Sérgio Flaksman. São Paulo: Ubu, 2017.

MONLEVADE, João. Construção da complexidade do financiamento da educação pública no Brasil. In: PINTO, José Marcelino; SOUZA, Silvana Aparecida de (Org.). Para onde vai 0 dinheiro? Caminhos e descaminhos do financiamento da educação. São Paulo: Xamã, 2014. p. 11-20.

OECD. Organização para a Cooperação e Desenvolvimento Econômico. Education at a glance 2017: OECD indicators. Paris: OECD, 2017.

ORAIR, Rodrigo Octávio; GOBETTI, Sérgio Wulff. Progressividade tributária: a agenda negligenciada. Rio de Janeiro: IPEA, 2016. (Texto para discussão; 2190).

PINTO, José Marcelino de Resende. Dinheiro traz felicidade? A relação entre insumos e qualidade na educação. Arquivos Analíticos de Políticas Educativas, [S. I.], v. 22, n. 19, p. 1-20, 2014.

PNE 2014-2024. Plano Nacional de Educação. Lei n 13.005, de 25 de junho de 2014. Brasília, DF: Câmara dos Deputados, 2014.

ROSSI, Pedro; DWECK, Ester. Impactos do novo regime fiscal na saúde e educação. Cadernos de Saúde Pública, Rio de Janeiro, v. 32, n. 12, p. 1-5, 2016.

ROSSI, Pedro; OLIVEIRA, Ana Luiza Mato de; ARANTES, Flávio. Austeridade e impactos no Brasil: ajuste fiscal, teto de gastos e o financiamento da educação pública. Friedrich Ebert Stiftung Brasil, análise n. 33, p. 1-19, 2017.

Recebido em: 03.10.2018

Revisado em: 26.06.2019

Aprovado em: 11.09.2019

Eduardo Carvalho Ferreira é doutor em educação pela Universidade de São Paulo (USP). É professor do Serviço Nacional de Aprendizagem Comercial (Senac) São Miguel Paulista. Realiza pesquisas a respeito de política e organização da educação básica, currículo, formação de professores e metodologia de ensino em ciências humanas e sociais. Atualmente é Pósdoutorando em Educação na Universidade Federal de São Paulo (Unifesp). 